\title{
Indicadores de estabilidad aeróbica en ensilajes de la mezcla Tithonia diversifolia/Pennisetum purpureum enriquecidos con Lactobacillus
}

\section{Indicators of aerobic stability in silages of the mixture Tithonia diversifolia/Pennisetum purpureum enriched with Lactobacillus}

\author{
Vilma A. Holguín ${ }^{1 *} ;$ Mario Cuchillo ${ }^{2}$; Jairo Mora-Delgado ${ }^{3}$ \\ 'Zootecnista, M.Sc., Ph.D. Universidad del Tolima, Departamento de Producción Pecuaria, Grupo de Investigación Sistemas Agroforestales Pecuarios. Ibagué \\ _. Tolima, Colombia; e-mail: vholguin@ut.edu.co; (D) https://orcid.org/0000-0003-2680-5846
}

${ }^{2}$ MVZ, Ph.D. Instituto Nacional de Ciencias Médicas y Nutrición "Salvador Zubirán". Ciudad de México, México; email: mario.cuchilloh@incmnsz.mx; (D)https://orcid. org/0000-0001-6985-3763

${ }^{3}$ Zootecnista, M.Sc., Ph.D. Universidad del Tolima, Departamento de Producción Pecuaria, Grupo de Investigación Sistemas Agroforestales Pecuarios. Ibagué Tolima, Colombia; e-mail:jrmora@ut.edu.co; (iD https://orcid.org/0000-0002-1093-4216

*autor para correspondencia: vholguin@ut.edu.co

Cómo citar: Holguín, V.A.; Cuchillo, M.; Mora-Delgado, J. 2021. Indicadores de estabilidad aeróbica en ensilajes de la mezcla Tithonia diversifolia/Pennisetum purpureum enriquecidos con Lactobacillus. Rev. U.D.C.A Act. \& Div. Cient. 24(2):e2093. http://doi.org/10.31910/ rudca.v24.n2.2021.2093

Artículo de acceso abierto publicado por Revista U.D.C.A Actualidad \& Divulgación Científica, bajo una Licencia Creative Commons CC BY-NC 4.0

Publicación oficial de la Universidad de Ciencias Aplicadas y Ambientales U.D.C.A, Institución de Educación Superior Acreditada de Alta Calidad por el Ministerio de Educación Nacional.

Recibido: marzo 27 de 2019

Aceptado: septiembre 20 de 2021

Editado por: Helber Adrián Arévalo Maldonado

\section{RESUMEN}

En épocas de escasez, los ganaderos recurren a conservar el alimento mediante procesos de fermentación anaeróbica, conocidos como ensilajes. Una vez que el silo es abierto, el sustrato resulta aeróbicamente estable, cuando, al momento de la apertura, conserva su integridad nutricional. Esto es el resultado de un ambiente ácido que restringe los efectos deletéreos de la acción de microrganismos patógenos, expresado en indicadores de estabilidad a la exposición aeróbica. Uno de los problemas empíricos que enfrenta el productor es resolver la pregunta de cómo evitar el deterioro del ensilaje, una vez es abierto, por lo cual, esta investigación apunta a la resistencia en el periodo de exposición aeróbica (PEA) de un ensilaje de Pennisetum purpureum (PP), con diferentes niveles de sustitución de Tithonia diversifolia (TD). El estudio, se adelantó en el Centro Internacional de Agricultura Tropical en Colombia. Con un ensilaje de 90 días de fermentación, se realizó una prueba de estabilidad aeróbica de siete días, usando ensilajes de un kilogramo, a diferentes proporciones (\%) de TD/ PP: 100/0, 67/33, 33/67 y 0/100, enriquecidos con dos aditivos 
basados en Lactobacillus. Se midió el cambio de la materia seca, temperatura y el $\mathrm{pH}$, encontrándose una estabilidad a la exposición aeróbica. El papel de TD es notable, una vez que el ensilado entra en el PEA, debido a la capacidad tampón que amortigua el cambio de $\mathrm{pH}$, una vez que se abre el silo, generando mayor estabilidad aeróbica.

Palabras clave: Acidez; Capacidad de búfer; Deterioro aeróbico; Variación térmica; Fermentación.

\section{ABSTRACT}

In times of scarcity, farmers resort to preserving food through anaerobic fermentation processes, known as silage. Once the silo is opened, the substrate is aerobically stable if it retains its nutritional integrity when opening. This is the result of an acidic environment that restricts the deleterious effects of the action of pathogenic microorganisms, expressed as indicators of stability to aerobic exposure. One of the empirical problems faced by the producer is to solve the question of how to avoid deterioration of the silage once it is opened, for which this research points to the resistance in the period of aerobic exposure (PEA) of a silage of Pennisetum purpureum (PP) with different levels of substitution of Tithonia diversifolia (TD). The study was conducted at the International Center for Tropical Agriculture in Colombia. With a 90-day fermentation silage, a seven-day aerobic stability test was carried out, using a kilogram silage at different proportions (\%) of TD/PP: 100/0, 67/33, 33/67 and 0/100 enriched with two Lactobacillus-based additives. The change in dry matter, temperature and $\mathrm{pH}$ was measured, finding stability to aerobic exposure. The role of TD is remarkable once the silage enters the PEA due to the buffer capacity that buffers the change in $\mathrm{pH}$ once the silo is opened, generating greater aerobic stability.

Keywords: Acidity; Buffer capacity; Aerobic deterioration; Thermal variation; Fermentation.

\section{INTRODUCCIÓN}

El propósito de hacer ensilaje es producir un forraje estable, con una alta conservación de la materia seca, energía y nutrientes digeribles después de la cosecha (Kung Jr. et al. 2018). En los sistemas de ganadería tropical, la inestabilidad aeróbica de los silos conlleva a pérdidas en el alimento, por lo tanto, se debe preparar en volúmenes apropiados, para administrarse en un corto lapso, después de la apertura.

Una vez abiertos los silos, la exposición aeróbica induce el desarrollo de poblaciones microbianas aerobias, iniciando la oxidación de los productos de fermentación presentes en el sustrato, causando un deterioro en la calidad, por la producción de sustancias o microorganismos tóxicos (Danner et al. 2003; Santos da Silva et al. 2014). Así, el ensilaje se torna aeróbicamente inestables, si en el periodo post apertura es invadido por microorganismos deletéreos, tales como mohos y levaduras (Borreani et al. 2018). Si estos microorganismos encuentran un ambiente favorable podrían ocasionar cambios en la coloración y la textura, como pérdidas de materia seca (DM) y nutrientes. El incremento de la actividad microbiana induce el aumento de la temperatura, así la estabilidad aeróbica se puede medir, evaluando este parámetro. El sustrato ensilado es aeróbicamente estable, si después de la exposición aeróbica mantiene una temperatura interna no superior a los $3{ }^{\circ} \mathrm{C}$ de diferencia respecto a la temperatura ambiente (Espinoza et al. 2017; Heinritz et al. 2012). El incremento de la temperatura constituye un indicador de la actividad de microrganismos aerobios, como mohos y las levaduras, proceso que puede ocasionar pérdidas de MS, si el incremento del consumo de nutrientes es considerable (Borreani et al. 2018).

El daño aeróbico de los ensilajes constituye un problema para la conservación de nutrientes, principalmente, por la fermentación alcohólica causada por levaduras y mohos, que asimilan el lactato (Pahlow et al. 2003). Frente a esto, los mecanismos para inducir la resistencia al deterioro aeróbico varían, entre ellos, los Lactobacillus heterofermentativos, que tienen una acción positiva, dado que producen ácido acético y propanodiol, además, decrece el número de levaduras y se incrementa el ácido acético en el ensilaje (Kung Jr. et al. 2018); esto contribuye a prolongar la resistencia aeróbica.

La inoculación con bacterias ácido-lácticas (BAL) heterofermentativas, como Lactobacillus brevis o Lactobacillus buchneri, aumenta la estabilidad (Danner et al. 2003); sin embargo, otras estrategias se podrían considerar para mitigar el deterioro, entre ellas, el ensilado de mezclas de plantas fuentes de energía y fibra con especies, que tienen la capacidad de producir altas concentraciones de ácido láctico en procesos de fermentación aeróbica, es decir, plantas con alta capacidad de mantener un $\mathrm{pH}$ bajo, cuando el silo es expuesto al aire (Mendieta-Araica et al. 2009).

Esta investigación parte de la hipótesis de que la sustitución de PP con TD en diferentes proporciones en el sustrato fermentado, aumenta la resistencia aeróbica. Por lo tanto, este experimento tiene como objetivo cuantificar el efecto de diferentes niveles de sustitución de la mezcla $T$. diversifolia/P. purpureum, enriquecidos con aditivos de Lactobacillus sobre la estabilidad del ensilaje, en el periodo de exposición aeróbica.

\section{MATERIALES Y MÉTODOS}

Los análisis, se realizaron en el Laboratorio de Calidad de Forrajes del Centro Internacional de Agricultura tropical - CIAT, en el Municipio de Palmira, Colombia, $3^{\circ} 30^{\prime} 09^{\prime \prime N}$; 76²1’18’W.

Preparación de los microsilos. El forraje utilizado para la producción de ensilaje fue recolectado en el Centro Experimental de la Universidad Nacional de Colombia - sede Palmira (CEUNP), en el Departamento del Valle del Cauca; área localizada a una altitud de $1.000 \mathrm{~m}$ s.n.m.; $2^{\circ} 06^{\prime} \mathrm{N}$ y $65^{\circ} 03^{\prime} \mathrm{W}$; presenta una precipitación anual media de $1.000 \mathrm{~mm}$ y temperatura media de $24^{\circ} \mathrm{C}$. Esta zona ha sido clasificada como tropical bosque seco (Holdridge, 2000). El forraje de Pennisetum purpureum y Tithonia diversifolia, se cosecharon en estado de prefloración. El forraje, se secó previamente durante 
24 horas; luego, se picó para reducir la partícula tamaño a $2 \mathrm{~cm}$, en un molino de tres palas, $7.5 \mathrm{HP}, 1.400 \mathrm{rpm}$ y 4.5 Amperios, marca Gaitán. Una vez que el forraje fue picado por separado para cada especie, se hizo una mezcla manual.

Los ensilajes, se almacenaron durante 90 días. Se mezclaron en cuatro niveles de sustitución de materia fresca, configurando cuatro proporciones de TD/PP, así: 100/0; 67/33; 33/67; 0/100. Cada proporción, se enriqueció con dos aditivos, para evaluar el efecto de inóculo: T735; SIL-ALL $® 4 \times 4$ y un control (sin inóculo). El inoculo T735 es una bacteria aislada de T. diversifolia, correspondiente a Lactobacilus paracasei, obtenido a partir de hojas maceradas, siguiendo el protocolo explicado por Holguín et al. (2018), desarrollado en el Laboratorio de Diagnóstico Veterinario de la Universidad del Tolima. La concentración del inóculo utilizado fue de 30 x 107 UFC mL-1, y SIL-ALL®4x4, que es una mezcla comercial de bacterias del ácido láctico Streptococcus faecium (CNCM I-3236), Lactobacillus plantarum (CNCM I-3235), Pediococcus acidilactici (CNCM I-3237) y Lactobacillus salivarius (CNCM I-3238).

A los 90 días, se hizo un análisis bromatológico de los microsilos (Tabla1). Se determinó fibra detergente neutra (FDN); fibra detergente ácida (FDA), según el método descrito por Van Soest \& Wine (1967); proteína cruda (PC), según el método de Kjeldahl (Nielsen, 1994) y Materia seca (MS) y cenizas, por medio del método de residuo mineral fijo, descritos por la AOAC (1990), verificándose la calidad bromatológica de los sustratos, donde los valores de PC, MS, FDA y FDN son consistentes con las mezclas y el proceso adecuado de fermentación láctica.

Estabilidad aeróbica. La prueba de estabilidad aeróbica, se realizó siguiendo los protocolos descritos por Honig (1990). Los tratamientos, se ensilaron en bolsas de polietileno, con una capacidad de $1 \mathrm{~kg}$ y se sellaron al vacío por triplicado. Luego, se liofilizaron y se almacenaron a una temperatura de, aproximadamente, $25^{\circ} \mathrm{C}$, durante $90 \mathrm{~d}$.
Para la evaluación en el PEA, los microensilajes fueron monitoreados durante siete días después de la apertura. Se hicieron mediciones de temperatura, el pH y la MS; para ello, los microsilos se abrieron y se introdujeron en recipientes de poliestireno de 60 $\mathrm{mm}$ de espesor; cada recipiente estaba equipado con termómetros digitales mínimos interiores y exteriores simples (IN-OUT THERMO, infactory, precisión de 0,5 y $0,1{ }^{\circ} \mathrm{C}$, respectivamente), para monitorear la temperatura del ambiente y de los sustratos de forma simultánea. Una desinfección con alcohol del sensor fue realizada después de cada medida. La temperatura, se monitoreo en tres ocasiones durante el día, a las 8,12 y 16 horas, durante todo el PEA de siete días consecutivos. El pH y la MS fueron medidos al momento de la apertura y a los siete días. La determinación del $\mathrm{pH}$, se hizo con un equipo marca Mettler-Toledo, modelo SG8, serie: B 337764747. La MS, se determinó mediante una estufa Presition ${ }^{\text {TM }}$, a $63{ }^{\circ} \mathrm{C}$, durante $72 \mathrm{~h}$.

Diseño experimental y análisis estadístico. Se usó un diseño experimental factorial (Tabla 2); el primer factor fue el nivel de inclusión en la mezcla TD/PP y el segundo, el inoculante (ecuación 1).

$Y i j=\mu+P P i+I j+I x T D / P P j+\varepsilon$

ecuación 1

Donde:

$\mathrm{Y}=$ es la variable objetivo

$\mu$ es el promedio general

$\mathrm{I}=$ inoculante

$\mathrm{TD} / \mathrm{PP}=$ proporción de $T$. diversifolia/ $\mathrm{P}$. purpureum en el ensilaje $\varepsilon=$ error experimental aleatorio

Se realizó una comparación estadística entre el día en que se abrió el silo y a los siete días después de abierto. Se usó medidas repetidas, siguiendo la subrutina "Estimación de modelos lineales generales y mixtos", asumiendo variaciones heterogéneas, mediante el software estadístico Infostat (Di Rienzo et al. 2008). Las diferencias

Tabla 1. Composición química de los ensilajes a los 90 días de fermentación.

\begin{tabular}{|c|c|c|c|c|c|}
\hline $\begin{array}{c}\text { Proporción } \\
\text { TD/PP }\end{array}$ & Inóculo & MS (\%) & PC (\%) & FDN (\%) & FDA (\%) \\
\hline \multirow{3}{*}{$1: 100 / 0$} & T-735 & 28 & 16,8 & 34,9 & 23,1 \\
\cline { 2 - 6 } & Sil-All & 29,6 & 15,9 & 34,7 & 24,4 \\
\cline { 2 - 5 } & No Inoc & 27,6 & 18,1 & 38,6 & 28,1 \\
\hline \multirow{3}{*}{$2: 67 / 33$} & T-735 & 25,8 & 12,7 & 40,8 & 28,3 \\
\cline { 2 - 6 } & Sil-All & 26,8 & 12,3 & 41,7 & 28,7 \\
\cline { 2 - 6 } & No Inoc & 24,6 & 15,1 & 43,3 & 29,9 \\
\hline \multirow{3}{*}{$3: 33 / 67$} & T-735 & 23,8 & 8,6 & 49,1 & 33,4 \\
\cline { 2 - 6 } & Sil-All & 22,8 & 9 & 49,3 & 33,9 \\
\cline { 2 - 6 } & No Inoc & 23,8 & 8,4 & 48,8 & 34,4 \\
\hline \multirow{3}{*}{$4: 0 / 100$} & T-735 & 18 & 5,3 & 57,3 & 38,2 \\
\cline { 2 - 6 } & Sil-All & 18,2 & 5,1 & 57,9 & 38,3 \\
\cline { 2 - 6 } & No Inoc & 19,8 & 5,1 & 57,9 & 39,1 \\
\hline
\end{tabular}

Proporciones: 1: 100/0; 2: 67/33; 3: 33/67; 4: 0/100; MS: materia seca; PC: proteína cruda; FDN: fibra detergente neutro; FDN: fibra detergente ácido. 
Tabla 2. Combinación de factores proporción e inoculo, para establecer los tratamientos.

\begin{tabular}{|c|c|c|c|}
\hline \multirow{2}{*}{ Proporción TD/PP } & \multicolumn{3}{|c|}{ Inóculo } \\
\cline { 2 - 4 } & A: No inóculo & B: T-735 & C: Sil-all (C) $4 \times 4$ \\
\hline $1: 100 / 0$ & T1 $(1 \mathrm{~A})$ & T5 $(1 \mathrm{~B})$ & T9 (1C) \\
\hline $2: 67 / 33$ & $\mathrm{~T} 2(2 \mathrm{~A})$ & $\mathrm{T} 6(2 \mathrm{~B})$ & $\mathrm{T} 10(2 \mathrm{C})$ \\
\hline $3: 33 / 67$ & $\mathrm{~T} 3(3 \mathrm{~A})$ & $\mathrm{T} 7(3 \mathrm{~B})$ & $\mathrm{T} 11(3 \mathrm{C})$ \\
\hline $4: 0 / 100$ & $\mathrm{~T} 4(4 \mathrm{~A})$ & $\mathrm{T} 8(4 \mathrm{~B})$ & $(4 \mathrm{C})$ \\
\hline
\end{tabular}

estadísticas, se detectaron mediante comparaciones de medias de Tukey $(\mathrm{p}<0,05)$.

\section{RESULTADOS Y DISCUSIÓN}

Las características químicas de los ensilajes a los 90 días mostraron una tendencia lógica en función de las proporciones TD/PP. La MS, se redujo a medida que se aumenta el nivel de inclusión de PP, siendo más bajos los valores en los ensilajes que contienen PP al $100 \%$ ( $\mathrm{p}<0,05)$; no se presentó efecto del inoculo ( $\mathrm{p}$ valor 0,2181 ). Los valores de PC fueron más altos en los ensilajes que contienen TD al $100 \%$; cabe señalar que, en este nivel de inclusión, la adición de inóculo no presentó ningún efecto favorable. A medida que se incrementa el nivel de inclusión de PP la proporción de FDN y FDA se incrementa, dada la composición química de las plantas C4 de poseer una pared celular mucho más gruesa respecto a las asteráceas. Con base en estas características del ensilaje, se hicieron los análisis de resistencia aeróbica a los 7 días de abiertos los microsilos.

Variación de la temperatura. No se presentaron diferencias significativas $(p>0,05)$ en el efecto de los inóculos ni en la interacción tratamiento-inóculo, por lo cual, se realiza el análisis de factores individuales. La figura 1 muestra que la temperatura del sustrato disminuye durante las primeras 24 horas y luego aumenta después del tercer día de exposición aeróbica (PEA), en las cuatro proporciones de TD/PP. La diferencia con respecto a la temperatura ambiente, alcanzado en los siete días posteriores a la apertura del silo en las cuatro proporciones, es evidente, principalmente, el aumento térmico de la proporción 4. En esta mezcla, se dio un aumento importante en la temperatura registrada en los primeros dos días de exposición aeróbica, posiblemente, debido a la baja capacidad búfer de la gramínea, que no amortiguó el rápido incremento del $\mathrm{pH}$ y como consecuencia una proliferación de microrganismos patógenos, que incrementan la respiración y, por tanto, el aumento de calor (Borreani et al. 2018).

En términos generales, la temperatura del sustrato alcanza una expresión máxima entre los días 4 y 5 del PEA y luego decae, estabilizándose alrededor de $27{ }^{\circ} \mathrm{C}$. El pico de alta temperatura alcanzado en la proporción 4 es sobresaliente, después de dos días del PEA, lo que sugiere una mayor intensidad en la actividad microbiana en este tratamiento; posiblemente, esto esté relacionado con un aumento del $\mathrm{pH}$, lo que hace que el ambiente sea más propicio para la actividad de los organismos aeróbicos.

La separación de las medias, en cada uno de estos días, indica que existen diferencias significativas entre las proporciones $(p<0,05)$, con un aumento evidente en la 4 (Figura 2).

Pese a que las proporciones con mayor proporción de $T$. diversifolia (1 y 2) son las que en el proceso de fermentación tienen mayor dificultad de bajar el $\mathrm{pH}$, presentando los valores más altos al momento de apertura, fueron las que presentaron una mayor estabilidad aeróbica. La menor diferencia de temperatura respecto al ambiente está relacionada con la menor actividad microbiana, dada la capacidad buffer de $T$. diversifolia, que inhibe el incremento de $\mathrm{pH}$, una vez se abre el silo, manteniendo un ambiente ácido más estable $y$, por tanto, restringiendo la proliferación de microorganismos no deseables.

El efecto tampón de las materias primas está relacionado directamente con el contenido de proteína. En general, las fuentes de proteína tienen una alta capacidad tampón, dado que su reacción selectiva con otra sustancia puede aumentar la unión de protones (Otthuis et al. 1994). Esto se explica, porque las moléculas nitrogenadas (aminoácidos y proteínas) presentes en los tejidos son electrolitos anfóteros, por lo cual, pueden ceder o captar protones y, dependiendo del $\mathrm{pH}$, se pueden desempeñar al mismo como ácido o como base. En un medio muy básico se cargan negativamente, mientras que, en el fuertemente ácido, lo hacen positivamente. En ese orden, los componentes intracelulares de origen proteico, con sus substancias ionizables a diferentes valores de $\mathrm{pH}$, aportan de manera el intercambio de $\mathrm{H}^{+}$con iones unidos a proteínas, mantenimiento el pH; éstos, normalmente, se mueven desde el exterior de las células, contribuyendo a mantener la neutralidad en el medio.

En cuanto a la temperatura del ensilaje con respecto al ambiente, los datos muestran una estabilidad a la exposición aeróbica, evidenciado en que el mayor incremento térmico, entre 3 y $5^{\circ} \mathrm{C}$ con respecto a la temperatura ambiente, se mantiene por un periodo menor a tres días consecutivos. Mendieta-Araica et al. (2009) sugieren que, cuando la temperatura del ensilaje sobrepasa estos umbrales por encima de la temperatura ambiente y se mantiene durante más del periodo indicado, el sustrato se considera como aeróbicamente inestable y el deterioro es esperado. Esto puede ser explicado con la proliferación de levaduras que actúan sobre el lactato y oxidan los ácidos láctico y acético y carbohidratos solubles en agua, produciendo $\mathrm{CO}_{2}$ y agua, con el incremento de calor (Navas \& Morales, 2016).

pH y materia seca en el periodo de exposición aeróbica. Los resultados de la MS y el pH determinado en la apertura y después 
de la prueba de estabilidad aeróbica a los 7 días, se muestran en la tabla 3 .

Respecto a los valores de MS, tanto en la apertura del ensilaje a los 90 días como después del PEA, se registraron diferencias significativas en la prueba de medias ( $\mathrm{p}<0,05)$, entre los niveles de sustitución, con una tendencia a aumentar la MS en los tratamientos, con una mayor proporción de TD. A su vez, los cambios en la MS después del período de exposición aeróbica (PEA), en comparación con la apertura a los 90 días, no fue significativo. Estos resultados, se constituyen en atípicos; Honig \& Woolford (1980) informan sobre pérdidas de MS y nutrientes que pueden oscilar entre 1,5 y 4,5\%
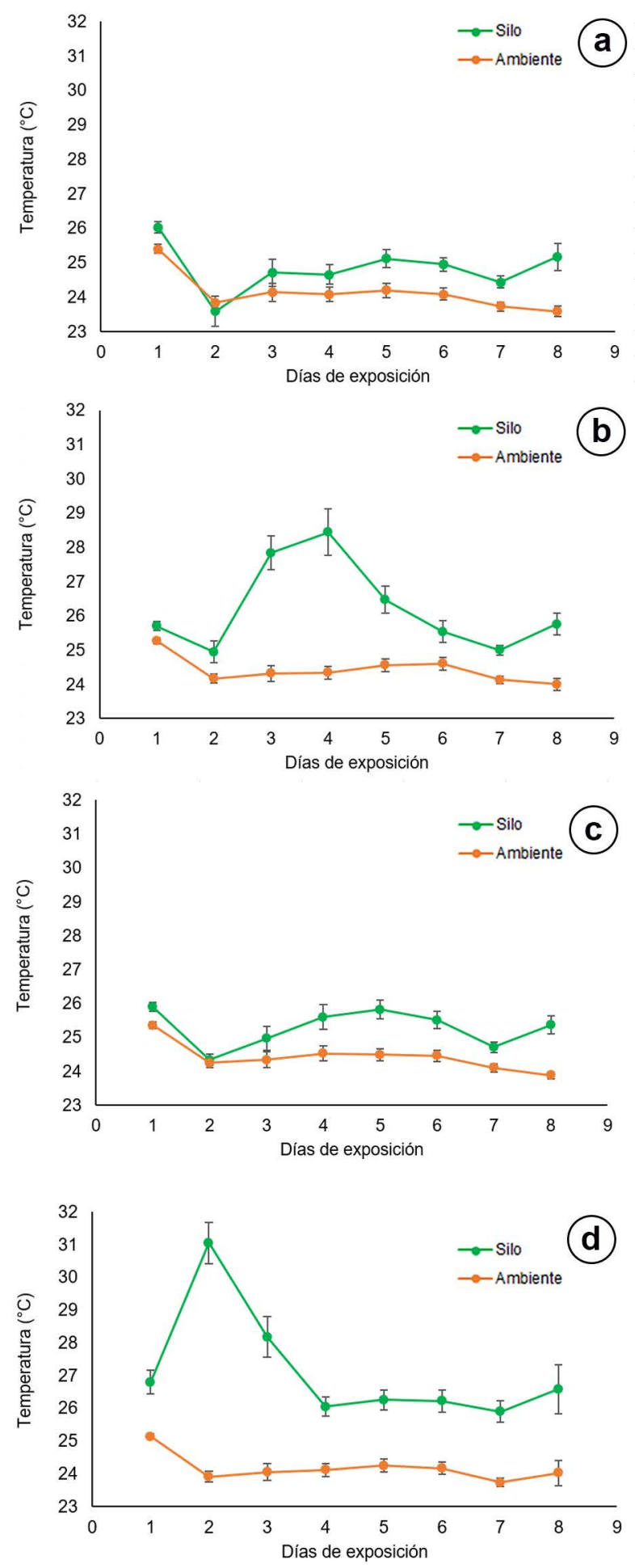

Figura 1. Temperatura ambiente y del ensilaje en el periodo de exposición aeróbica de la mezcla Tithonia diversifolia/Pennisetum purpureum. a. 1: 100/0; b. 2: 67/33; c. 3: 33/67; d. 4: 0/100.purpureum. a. 1: 100/0; b. 2: 67/33; c. 3: 33/67; d. 4: 0/100. 
diariamente, después de la exposición a condiciones aeróbicas, incluso, Borreani et al. 2018 y Bernardes et al. (2012), mencionan que las pérdidas se pueden incrementar hasta el $20 \%$ del total de MS almacenada de ensilajes agrícolas, tanto en clima templado como en climas cálidos.

Por el contrario, el estudio de Gerlacha et al. (2014) presenta resultados con una ligera concentración del material sólido después de la exposición a condiciones aeróbicas, cambiando del 29 al 29,8 \%, en un PEA, de 7 días. Los valores de la MS medidos son más bajos que los reportados por otros autores en ensilajes de pastos y otras especies, como asteráceas y fabáceas; por ejemplo, Ávila et al. (2009) y Jones et al. (2004) informaron un 41,8 y $28,8 \%$ de MS, respectivamente, en ensilajes de sorgo; esto demuestra que las condiciones del ambiente de ensilaje, expresadas en temperatura y $\mathrm{pH}$, pueden ser determinantes en la conservación de nutrientes en el proceso de ensilaje; así un medio ácido y bajas temperaturas, significa eficiente fermentación, limitará la proliferación de microorganismos indeseables y reducirá las proteólisis y consumo de materia seca, mientras que un ambiente inadecuado, se reflejará en pérdida de nutrientes y, por tanto, de materia seca (Borreani et al. 2018).

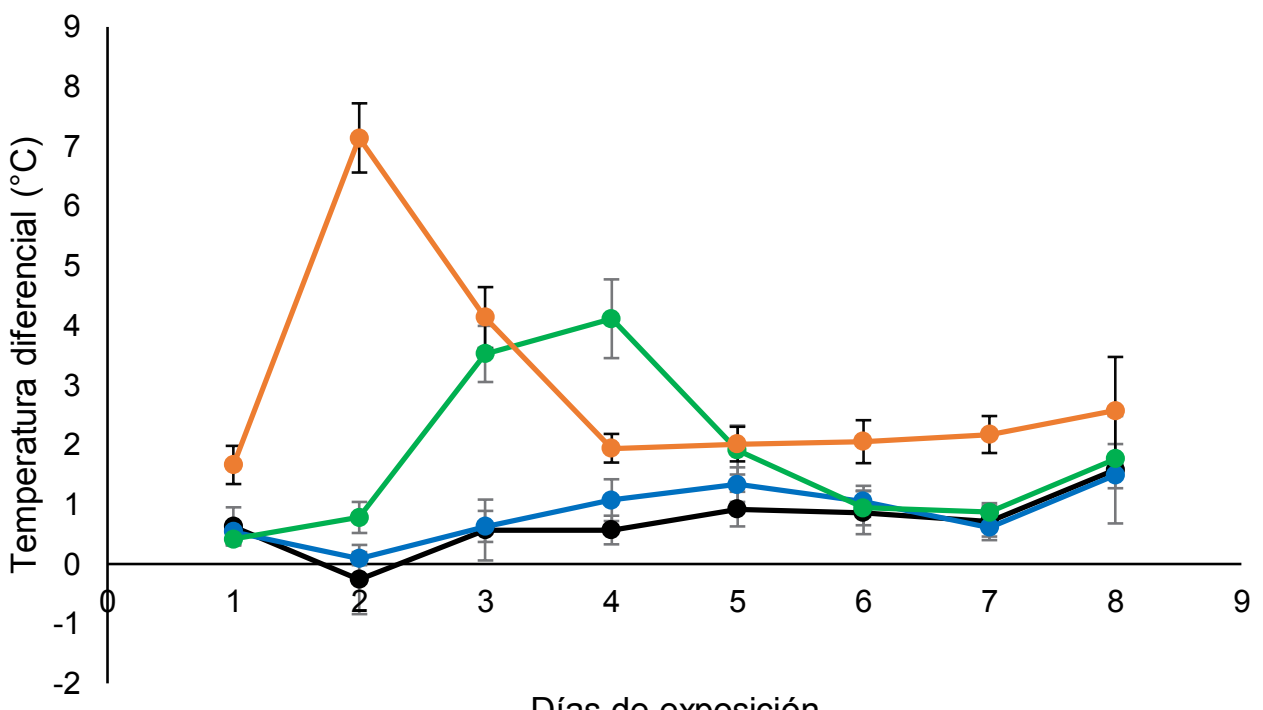

Días de exposición

$\longrightarrow 1:(100 / 0) \multimap 2:(67 / 33) \multimap 3:(33 / 67) \multimap 4:(0 / 100)$

Figura 2. Variación térmica en el período de exposición aeróbica de los ensilajes de la mezcla Tithonia diversifolia/Pennisetum purpureum.

Ensilajes con bajo contenido de MS presenta fermentación indeseable, además, que los efluentes pueden causar focos de contaminación; así, cuando presenta valores menores a $30 \%$, se inducen fermentaciones prolongadas, debido a su mayor capacidad búfer; sin embargo, en el presente estudio, los tratamientos registraron porcentajes de MS menores a esta cifra sin pérdidas, ni deterioro de sus propiedades.
Cabe advertir que, cuando ocurren procesos respiratorios dentro de un silo, la humedad puede aumentar, produciéndose los lixiviados y disminuir la MS, a través del tiempo de fermentación, constituyendo en uno de los indicadores de deterioro aeróbico, ya que puede oxidar el lactato y el acetato produciendo CO2 y agua (Oude et al. 1999).

Tabla 3. Variación de la MS en el período de exposición aeróbica de los ensilajes de Penisetum purpureum en mezcla con Tithonia diversifolia.

\begin{tabular}{|c|c|c|c|}
\hline Proporción & Apertura & 7 días MS & Diferencia \\
\cline { 2 - 4 } TD/PP & \multicolumn{3}{|c|}{$\mathbf{( \% )}$} \\
\hline $1: 100 / 0$ & $28,39 \pm 1,06 \mathrm{~d}$ & $30,3 \pm 0,95 \mathrm{c}$ & $1,91 \pm 0,80 \mathrm{a}$ \\
\hline $2: 67 / 33$ & $25,75 \pm 1,43 \mathrm{c}$ & $26,74 \pm 1,05 \mathrm{~b}$ & $0,99 \pm 1,65 \mathrm{a}$ \\
\hline $3: 33 / 67$ & $23,45 \pm 0,89 \mathrm{~b}$ & $24,59 \pm 1,62 \mathrm{~b}$ & $1,14 \pm 1,58 \mathrm{a}$ \\
\hline $4: 0 / 100$ & $18,67 \pm 0,90 \mathrm{a}$ & $21,05 \pm 5,49 \mathrm{a}$ & $2,38 \pm 4,90 \mathrm{a}$ \\
\hline
\end{tabular}

Letras iguales no son significativamente diferentes ( $p>0,05)$.diversifolia. 
Tabla 4. Variación del pH en el período de exposición aeróbica de los ensilajes de la mezcla Tithonia diversifolia / Pennisetum purpureum enriquecida con o sin inóculo de Lactobacillus (T-735 y Sil-all (C4x4).

\begin{tabular}{|c|c|c|c|c|}
\hline \multirow{2}{*}{$\begin{array}{c}\text { Proporción } \\
\text { TD/PP }\end{array}$} & Inóculo & \multicolumn{3}{|c|}{$\mathrm{pH}$} \\
\cline { 3 - 5 } & & Apertura & 7 días & Cambio \\
\hline \multirow{3}{*}{$1: 100 / 0$} & T-735 & $4,17 \pm 0,03 \mathrm{ef}$ & $5,01 \pm 1,59 \mathrm{a}$ & $0,85 \pm 1,60 \mathrm{abc}$ \\
\cline { 2 - 5 } & SilAll & $4,26 \pm 0.05 \mathrm{f}$ & $4,58 \pm 0,55 \mathrm{a}$ & $0,32 \pm 0,57 \mathrm{ab}$ \\
\cline { 2 - 5 } & Sin inoculo & $4,43 \pm 0,08 \mathrm{~g}$ & $4,49 \pm 0,06 \mathrm{a}$ & $0,06 \pm 0,03 \mathrm{a}$ \\
\hline \multirow{3}{*}{$2: 67 / 33$} & T-735 & $4,06 \pm 0,06 \mathrm{cde}$ & $5,12 \pm 1,48 \mathrm{a}$ & $1,06 \pm 1,52 \mathrm{abc}$ \\
\cline { 2 - 5 } & SilAll & $4,1 \pm 0,05 \mathrm{de}$ & $5,72 \pm 1,83 \mathrm{a}$ & $1,62 \pm 0,86 \mathrm{abc}$ \\
\cline { 2 - 5 } & Sin inoculo & $4,3 \pm 0.11 \mathrm{fg}$ & $4,34 \pm 0,07 \mathrm{a}$ & $0,04 \pm 0.05 \mathrm{a}$ \\
\hline \multirow{3}{*}{$3: 33 / 67$} & T.735 & $3,95 \pm 0,02 \mathrm{bcd}$ & $6,45 \pm 0,55 \mathrm{a}$ & $2,5 \pm 0,54 \mathrm{abc}$ \\
\cline { 2 - 5 } & SilAll & $4,01 \pm 0,04 \mathrm{~cd}$ & $6,67 \pm 0,60 \mathrm{a}$ & $2,66 \pm 0,56 \mathrm{bc}$ \\
\cline { 2 - 5 } & Sin inoculo & $4,05 \pm 0,09 \mathrm{cde}$ & $6,25 \pm 1,46 \mathrm{a}$ & $2,21 \pm 1,44 \mathrm{abc}$ \\
\hline \multirow{3}{*}{$4: 0 / 100$} & T-735 & $3,76 \pm 0,03 \mathrm{a}$ & $6,86 \pm 0,17 \mathrm{a}$ & $3,11 \pm 0,15 \mathrm{c}$ \\
\cline { 2 - 5 } & SilAll & $3,82 \pm 0,04 \mathrm{ab}$ & $6,74 \pm 0,35 \mathrm{a}$ & $2,92 \pm 0,37 \mathrm{c}$ \\
\cline { 2 - 5 } & Sin inoculo & $3,92 \pm 0,07 \mathrm{bc}$ & $6,33 \pm 1,11 \mathrm{a}$ & $2,41 \pm 1,06 \mathrm{abc}$ \\
\hline
\end{tabular}

Letras iguales no son significativamente diferentes $(\mathrm{p}>0,05)$.

Con relación al $\mathrm{pH}$, al momento de la apertura de los microsilos (Tabla 4), se registran diferencias entre las cuatro proporciones $(\mathrm{p}$ $<0,0001)$ y entre los aditivos de BAL ( $p<0,0001$ ), pero no hubo diferencias en la interacción $(\mathrm{p}=0,0802)$. En todas las proporciones, los ensilajes inoculados con la cepa T-735 fueron los que presentaron el pH más bajo, seguidos de los sustratos enriquecidos con SIL-ALL $囚 4 x 4$; el ensilaje sin inóculo registró el $\mathrm{pH}$ promedio más alto ( $<<0,05)$. Martens et al. (2014) demostraron que el uso de carbohidratos en combinación con cepas de bacterias ácidas podría mejorar la fermentación de forrajes tropicales; así, la combinación de Lactobacillus y la sacarosa, generalmente, incrementan la tasa de reducción del pH, en la mayoría de las gramíneas (Hoedtke \& Zeyner, 2011).

El análisis de diferencia de medias para la variable de $\mathrm{pH}$ indica significancia entre las proporciones al momento de la apertura del silo; igualmente, en los valores de cambio de $\mathrm{pH}$ en el PEA, al día siete. La prueba de Tukey $(\mathrm{p}<0,05)$ indica diferencias estadísticas entre proporciones, pero no hubo efecto de inóculo $(\mathrm{p}=0,0986) \mathrm{ni}$ en la interacción ( $\mathrm{p}=0,8602)$.

En el PEA, los datos confirman que el $\mathrm{pH}$ aumenta a medida que se incrementa la proporción de PP en la mezcla. Ensilajes con alta proporción de PP, como en general sucede con altos contenidos de gramíneas en el sustrato ensilable, tienen una baja capacidad búfer, que resulta en rápido incremento de la acidez en el PEA.

En el momento de la apertura de los silos es evidente que la mayor proporción de la gramínea (PP) en la mezcla, probablemente, restringe la capacidad búfer de $T$. diversifolia, lo que explica los valores de $\mathrm{pH}$ más bajos en las mezclas, con un mayor porcentaje de inclusión de P. purpureum (Proporciones 3 y 4) y, por el contrario, los ensilajes con mayor proporción de TD, presentaron los valores más altos de $\mathrm{pH}(1$ y 2$)$; sin embargo, después de la prueba de estabilidad aeróbica, a los siete días, el pH obtenido, mostró diferencias respecto a los valores al momento de la apertura, con una variación significativa $(p<0,05)$, especialmente, en la proporción 4. Solo para la proporción 1 , no se presentó diferencia $(\mathrm{p}=0,1366)$, lo cual, indica una mayor estabilidad en el sustrato de TD, al $100 \%$.

Así, el papel de la TD es evidente como amortiguadora del cambio de $\mathrm{pH}$, ya que su alta capacidad búfer tiene un efecto estabilizador en el del medio ácido, una vez que se abre el silo. Autores, como Holguín et al. (2018) y Kung Jr. et al. (2018) han demostrado que la capacidad buffer es alta para alimentos ricos en proteínas, mientras que es baja para alimentos energéticos y las gramíneas.

Por otra parte, la relación carbohidratos solubles en agua/capacidad buffer (CSA/BC) de TD, indica su baja idoneidad para el ensilado en comparación con PP, o su alta proporción en la mezcla, que tiene una mejor relación CSA/BC; Heinritz et al. (2012) afirman que, entre mayor sea esta relación, mayor será la ensilabilidad y, por tanto, la estabilidad del ambiente ácido. Este hallazgo ayuda a explicar por qué los valores de $\mathrm{pH}$ son más bajos en mezclas con un mayor porcentaje de PP, pues la CB más baja de las gramíneas hace que el ambiente ácido se torne más bajo y en menos tiempo.

Se resalta, como puntos relevantes de este estudio, que la variación de la temperatura en el PEA no superó los $3^{\circ} \mathrm{C}$ durante más de tres días, lo que confirma la estabilidad aeróbica del ensilaje.

El efecto de TD en la estabilidad aeróbica del ensilaje es positivo, dada su capacidad búfer al evitar un incremento de $\mathrm{pH}$, una vez 
que se abre el silo. Por lo tanto, la mayor estabilidad aeróbica se produce en los ensilajes, con una mayor proporción de TD (proporciones 1 y 2), que en aquellos con una mayor proporción de PP (3 y 4). De acuerdo con los resultados, la mejor proporción es 1:100/0; sin embargo, desde el punto de vista zootécnico, sería más recomendable usar un ensilaje de una mezcla de una fuente de proteína y una fuente energética fibrosa, para así mantener una relación proteína/energía adecuada y evitar problemas metabólicos.

Agradecimientos. Al Centro Internacional de Agricultura Tropical (CIAT) por el espacio facilitado para el desarrollo del trabajo de campo, especialmente, a Johanna Mazabel y Steven Quintero, profesionales de laboratorio; a la Universidad del Tolima, por el financiamiento del tiempo de los investigadores en este experimento. Conflicto de intereses: El manuscrito es parte de la tesis doctoral titulada "Optimización de Tithonia diversifolia ensilada como alimento para ovinos de pelo", realizada por la primera autora. Este artículo fue preparado y revisado con la participación de todos los autores, quienes declaramos que no existe conflicto de intereses que ponga en riesgo la validez de los resultados presentados.

\section{REFERENCIAS}

\section{ASSOCIATION OF OFFICIAL ANALYTICAL CHEMISTS,} AOAC. 1990. Official Methods of Analysis. Washington, D.C.

2. ÁVILA, C.L.S.; PINTO, J.C.; FIGUEREIDO, H.C.P.; SCHWANT, R.F. 2009. Effects of an indigenous and a commercial Lactobacillus buchneri strain on quality of sugar care silage. The Journal of the British Grassland Society. Grass and Forage Science. 64(4):384-399.

https://doi.org/10.1111/j.1365-2494.2009.00703.x

3. BERNARDES, T.F.; NUSSIO, L.G.; DO AMARAL, R.C. 2012. Top spoilage losses in maize silage sealed with plastic films with different permeabilities to oxygen. Grass Forage Sci. 67:34-42.

https://doi.org/10.1111/j.1365-2494.2011.00823.x

4. BORREANI, G.; TABACCO, E.; SCHMIDT, R.J.; HOLMES, B.J.; MUCK, R.E. 2018. Silage review: Factors affecting dry matter and quality losses in silages. Journal of Dairy Science. 101(5):3952-3979.

https://doi.org/10.3168/jds.2017-13837

5. DANNER, H.; HOLZER, M.; MAYRJUBER, E.; BRAUN, R. 2003. Acetic Acid increases stability of silage under aerobic conditions. Applied and Environmental Microbiology. 691:562-567.

https://doi.org/10.1128/AEM.69.1.562-567.2003

6. DI RIENZO, J.A.; CASANOVES, F.; BALZARINI, M.G.; GONZÁLEZ, L.; TABLADA, M.; ROBLEDO, C.W. 2008. InfoStat, versión 2008, Grupo InfoStat, FCA, Universidad
Nacional de Córdoba, Argentina.

7. ESPINOZA, I.; MONTENEGRO, B.; RIVAS, J.; ROMERO, M.; GARCIA, A.; MARTINEZ, A. 2017. Características microbianas, estabilidad aeróbica y cinética de degradación ruminal del ensilado de pasto saboya (Megatbyrsus maximus) con niveles crecientes de cáscara de maracuyá (Passifora edulis). Revista Científica. 27(4):241-248.

8. GERLACHA, K.; ROß, F.; WEIß, K.; BÜSCHERB, W.; SÜDEKUM, K.H. 2014. Aerobic exposure of grass silages and its impact on dry matter intake and preference by goats. Small Ruminant Research. 117(2-3):131-141.

https://doi.org/10.1016/j.smallrumres.2013.12.033

9. HEINRITZ, S.; MARTENS, S.D.; AVILA, P.; HOEDTKE, S. 2012. The effect of inoculant and sucrose addition on the silage quality of tropical forage legumes with varying ensilability. Animal Feed Science and Technology. 174(3-4):201-210.

https://doi.org/10.1016/j.anifeedsci.2012.03.017

10. HOEDTKE, S.; ZEYNER, A. 2011. Comparative evaluation of laboratory-scale silages using standard glass jar silages or vacuum-packed model silages. Journal of the Science of Food and Agriculture. 91(5):841-849.

https://doi.org/10.1002/jsfa.4255

11. HOLDRIDGE, L.R. 2000. Ecología basada en zonas de vida. Instituto Interamericano de Cooperación para la Agricultura (Costa Rica). p.215

12. HOLGUÍN, V.A.; CUCHILLO-HILARIO, M.; MAZABELPARRA, J.; MARTENS, S. 2018. In-vitro assessment for ensilabillity of Tithonia diversifolia alone or with Pennisetum purpureum using epiphytic lactic acid bacteria strains as inocula. Acta Scientiarum. Animal Sciences. 40:e37940 https://doi.org/10.4025/actascianimsci.v40i1.37940

13. HONIG, H. 1990. Evaluation of aerobic stability. Proceedings of the EUROBAC Conference, 12-16 August 1986, Uppsala. GrovFoder Grass and Forage Reports. Spec. 3:76-82.

14. HONIG, H.; WOOLFORD, M.K. 1980. Changes in silage on exposure to air. En: Thomas, C. (Ed.). Forage Conservation in the 80s. British Grassland Society (Hurley, Berkshire, UK).

15. JONES, C.M.; HEINRICHS, A.J.; ROTH, G.W.; ISHER, V.A. 2004. From harvest to feed: Understanding silage management. Pennsylvania State University. College of Agricultural Sciences (Pennsylvania). 36p.

16. KUNG JR., L.; SHAVER, R.D.; GRANT, R.J.; SCHMIDT, R.J. 2018. Silage review: Interpretation of chemical, microbial, and organoleptic components of silages. Journal of Dairy Science. 101(5):4020-4033. https://doi.org/10.3168/jds.2017-13909 
17. MARTENS, S.D.; HOEDTKE, S.; AVILA, P.; HEINRITZ, S.N.; ZEYNER, A. 2014. Effect of ensiling treatment on secondary compounds and amino acid profile of tropical forage legumes, and implications for their pig feeding potential. Journal of the Science of Food and Agriculture, 94(6):1107-1115.

https://doi.org/10.1002/jsfa.6375

18. MENDIETA-ARAICA B.; SPÖRNDLY, E.; REYESSÁNCHEZ, N.; NORELL, L.; SPÖRNDLY, R. 2009. Silage quality when Moringa oleifera is ensiled in mixtures with Elephant grass, sugar cane and molasses. Grass and Forage Science. 64(4):364-373.

https://doi.org/10.1111/j.1365-2494.2009.00701.x

19. NAVAS, J.A.; MORALES, D.A. 2016. Libro de texto de microbiología pecuaria. Universidad Nacional Agraria (Nicaragua). 128p.

20. NIELSEN, S. 1994. Introduction to the Chemical Analysis of foods. Ed. Jones and Bartlett Piblishers. (U.S.A.). 530p.

21. OTTHUIS, W.; LUO, J.; BERGVELD, P. 1994. Characterization of proteins by means of their buffering capacity, measured with an ISFET- based colorimetric sensor-actuator system. Biosensors and bioelectronics. 9(9-10):743-751. https://doi.org/10.1016/0956-5663(94)80073-1
22. OUDE, S.J.W.H.; DRIEHUIS, F.; GOTTSCHAL, J.C.; SPOELSTRA, S.F. 1999. Estudio 2.0 - Los procesos de fermentación del ensilaje y su manipulación. In: Mannetje, L.T. (ed.). Uso del Ensilaje en el Trópico Privilegiando Opciones para Pequeños Campesinos. N.161 FAO, Roma. Disponible desde Internet en: http://www.fao.org/3/X8486S/x8486s04.htm\#bm04 (con acceso el 15/01/2019)

23. PAHLOW, G.; MUCK, R.E.; DRIEHUIS, F.; OUDE ELFERINK, S.J.W.H.; SPOELSTRA, S.F. 2003. Microbiology of Ensiling. In: Buxton, D.R.; Muck, R.E.; Harrison, J.H. (eds.). Silage Science and Technology. American Society of Agronomy. 63p. https://doi.org/10.2134/agronmonogr42.c2

24. SANTOS DA SILVA, W.; CARVALHO DOS SANTOS, T.M.; CAVALCANTI NETO, C.C.; FILHO ESPINDOLA, A.M.; MESQUITA DA SILVA, S.G.; NEVES FIGUEIREDO, A.; ARAÚJO DE MELO, B. 2014. Características y estabilidad aeróbica de ensilajes de caña de azúcar, tratada con urea, $\mathrm{NaOH}$ y maíz. Pastos y Forrajes. 37(2):241-247.

25. VAN SOEST, P.J.; WINE, R.H. 1967. Use of detergents in the of fibrous feeds. Journal of Association of Official Analytical Chemists. 50(1):50-55. 